\title{
Crystal Structure and Magnetic Properties of (Fe,Si,Al)-Based Nanocomposite Magnets Designed for Cryogenic Applications
}

\begin{abstract}
MARIA DANIIL, HELEN M. FONDA, and MATTHEW A. WILLARD
In this work, we performed a detailed study of the crystallization, crystal structure, and magnetic properties of $\mathrm{Fe}_{87-z} \mathrm{Si}_{z-x} \mathrm{Al}_{x} \mathrm{Nb}_{3} \mathrm{~B}_{9} \mathrm{Cu}_{1}$ nanocrystalline alloys that were designed primarily for low-temperature applications. In addition, their interesting low-temperature $[77 \mathrm{~K}$ to $300 \mathrm{~K}$ $\left(-196{ }^{\circ} \mathrm{C}\right.$ to $\left.\left.27^{\circ} \mathrm{C}\right)\right]$ magnetic properties $\left(H_{\mathrm{c}}\right.$ and $\left.M_{\mathrm{s}}\right)$ were also investigated. These alloys were produced by annealing their amorphous precursors at $823 \mathrm{~K}\left(550^{\circ} \mathrm{C}\right)$. $\mathrm{Si}$ and $\mathrm{Al}$ substitution do not seem to alter the crystallization procedure and crystal structure of the parent alloy but reduces the lattice parameter, the Curie temperature, and the saturation magnetization. On the other hand, it improves the room temperature coercivity at small amounts $\left(H_{\mathrm{c}}=0.35 \mathrm{~A} / \mathrm{m}\right.$ for $x=3.5, z=19)$ and changes its temperature dependence. As a result, a remarkably low $H_{\mathrm{c}}$ value at $77 \mathrm{~K}\left(-196{ }^{\circ} \mathrm{C}\right)$ of $0.45 \mathrm{~A} / \mathrm{m}$ was observed for $x=6$ and $z=23.5$.
\end{abstract}

DOI: $10.1007 / \mathrm{s} 40553-015-0051-\mathrm{z}$

(C) ASM International (ASM) and The Minerals, Metals \& Materials Society (TMS) 2015

\section{INTRODUCTION}

FOR decades, Finemet [e.g., $\left.\mathrm{Fe}_{73.5} \mathrm{Si}_{13.5} \mathrm{Nb}_{3} \mathrm{~B}_{9} \mathrm{Cu}_{1}\right]$ has been a leading material for soft magnet applications at room temperature. ${ }^{[1]}$ Its excellent soft magnetic properties have been attributed to the very fine microstructure that results in nearly zero effective magnetocrystalline anisotropy ${ }^{[2,3]}$ and very small magnetostriction. ${ }^{[4]}$ Due to its successful room temperature performance, a recent study by Claassen ${ }^{[5]}$ investigated Finemet for use in cryogenic environments to support superconducting motor and cryogenic power converter technologies. The study revealed that the core losses of Finemet increase by nearly 300 pct compared to its room temperature value. Other materials designed for room temperature use have also been investigated for cryogenic applications, exhibiting varying degrees of degraded performance. ${ }^{[5-9]}$ With all of the materials investigated showing some performance degradation due to the cryogenic environment, it is clear that there is room for new alloys specifically designed for cryogenic temperatures if ferromagnetic materials are going to be considered for use within the cryostat.

Previous work by our group showed that proper substitutions of $\mathrm{Fe}$ with $\mathrm{Al}$ and $\mathrm{Si}$ in the $(\mathrm{Fe}, \mathrm{Si})$-based nanocrystalline alloys can improve the magnetic properties both at ambient and liquid nitrogen environments. ${ }^{[10]}$ In the present work, we investigate the crystallization behavior, crystal structure, Curie tem-

MARIA DANIIL, Researcher, and MATTHEW A. WILLARD, Associate Professor, are with the Department of Materials Science and Engineering, Case Western Reserve University, Cleveland, OH 44106. Contact e-mail: maw169@case.edu HELEN M. FONDA, Research Analyst, formerly with the Physics Department, Johns Hopkins University, Baltimore, MD 21218, is now with the Department of Justice, Washington, DC.

Manuscript submitted March 25, 2015.

Article published online May 19, 2015 perature, magnetostriction, and temperature dependence of saturation magnetization and coercivity of $\mathrm{Fe}-\mathrm{Si}-\mathrm{Al}-\mathrm{Nb}-\mathrm{Cu}$ alloys. The alloy design principles for the $\mathrm{Al} / \mathrm{Si}$ substitution were inspired by the work of Takahashi et al. on single crystalline and polycrystalline Sendust alloy ( 7 to $11 \mathrm{wt}$ pet Si, 4 to $7 \mathrm{wt}$ pct Al, bal. $\mathrm{Fe}){ }^{[11,12]}$ In their work, the temperature dependence of magnetocrystalline anisotropy $\left(K_{1}\right)$ and magnetostriction coefficients $\left(\lambda_{100}, \lambda_{111}\right)$ for $\mathrm{Fe}-\mathrm{Si}-\mathrm{Al}$ compositions close to the Sendust alloy were examined. They found the temperature at which $K_{1}$ and $\lambda_{\mathrm{s}}$ near zero depends sensitively on the Fe-Si-Al composition. The minimum temperature at which these two criteria were satisfied was $195 \mathrm{~K}$ (or $-78^{\circ} \mathrm{C}$ ). In the present study, we have used a linear extrapolation of the Takahashi data to identify a composition region with potentially low values of $K_{1}$ and $\lambda_{\mathrm{s}}$ at $77 \mathrm{~K}\left(-196{ }^{\circ} \mathrm{C}\right)$.

\section{EXPERIMENTAL PROCEDURE}

Amorphous ribbons with composition $\mathrm{Fe}_{87-z}$ $\mathrm{Si}_{z-x} \mathrm{Al}_{x} \mathrm{Nb}_{3} \mathrm{~B}_{9} \mathrm{Cu}_{1}$ where $(x, z)=(0,13.5)$, $(3.5,19)$, $(5,21.5),(6,23.5),(7,25)$ were prepared using a single roller melt spinner with a surface speed of $50 \mathrm{~m} / \mathrm{s}$ and an orifice of $0.75 \mathrm{~mm}$ in a $\mathrm{He}$ environment. The ribbons produced had a thickness of $\sim 20 \mu \mathrm{m}$, width of 2 to $3 \mathrm{~mm}$, and lengths between a few centimeters and several meters. The as-spun ribbons were annealed isothermally at $823 \mathrm{~K}$ and $1023 \mathrm{~K} \quad\left(550{ }^{\circ} \mathrm{C}\right.$ and $750{ }^{\circ} \mathrm{C}$ ) for 3600 seconds in an Argon atmosphere and then quenched rapidly in water. The crystallization process was examined by differential thermal analysis (DTA) using a TA instruments SDT2960 at a heating rate of $20 \mathrm{~K}\left(-253^{\circ} \mathrm{C}\right) / \mathrm{min}$. The crystal structure of the as-spun and annealed ribbons was examined using a Philips APD 3520 X-ray diffractometer (XRD). The 
measurements were performed on $\sim 1$-cm-long pieces of ribbons using $\mathrm{Cu} K_{\alpha}$ radiation. From the XRD patterns, we calculated the lattice constants of the crystalline phase (by fitting the diffraction peaks and using the $\cos ^{2} \theta / \sin \theta$ method) and the grain size (using the Scherrer equation). ${ }^{[13]}$ The magnetic hysteresis loops and thermomagnetic measurements were measured using an ADE Model $4 \mathrm{HF}$ vibrating sample magnetometer (VSM). During these measurements, a piece of ribbon 5-7-mm long was mounted with its long dimension parallel to the external field in order to minimize the demagnetizing field effect. The hysteresis loops of the samples annealed at $823 \mathrm{~K}\left(550^{\circ} \mathrm{C}\right)$ were measured at temperatures between $77 \mathrm{~K}$ and $300 \mathrm{~K}\left(-196{ }^{\circ} \mathrm{C}\right.$ and $27^{\circ} \mathrm{C}$ ) and with applied fields up to $1.592 \mathrm{MA} / \mathrm{m}$ $(20 \mathrm{kOe})$. For the determination of the coercivity, each ribbon piece was measured 5 to 10 times and an average value was obtained. Thermomagnetic measurements were conducted under an applied field of $3.18 \mathrm{kA} / \mathrm{m}$ (40 Oe) from 25 to $350{ }^{\circ} \mathrm{C}$. Transmission electron microscopy (TEM) was carried out to examine the refined grain microstructure using a Philips CM-30 analytical transmission electron microscope. Samples for TEM were prepared by ion milling using a Fischione ion mill with a gun voltage of $5 \mathrm{kV}$, current of $5 \mathrm{~mA}$,

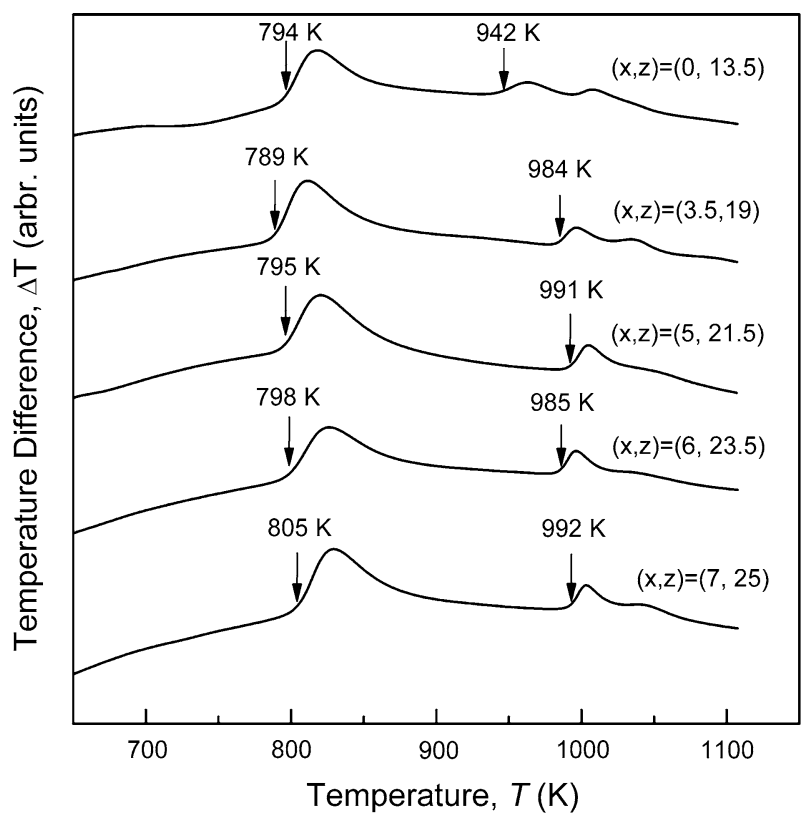

Fig. 1-Differential Thermal Analysis scans of the amorphous asspun ribbons at a heating rate of $20 \mathrm{~K}\left(-253{ }^{\circ} \mathrm{C}\right) / \mathrm{min}$ for $\mathrm{Fe}_{87-z} \mathrm{Si}_{z-x} \mathrm{Al}_{x} \mathrm{Nb}_{3} \mathrm{~B}_{9} \mathrm{Cu}_{1}$ alloys. and sputtering angle of $12 \mathrm{deg}$. Magnetostriction measurements were performed using strain gage-based techniques described in Reference 14.

\section{RESULTS AND DISCUSSION}

Figure 1 shows the DTA scans of the as-spun ribbons with the values of the onset of the crystallization temperatures presented in Table I. All compositions show two strong exothermic peaks that are well separated from each other. The first one occurs between $810 \mathrm{~K}$ and $829 \mathrm{~K}\left(537{ }^{\circ} \mathrm{C}\right.$ and $\left.556{ }^{\circ} \mathrm{C}\right)$ and the second between $961 \mathrm{~K}$ and $1003 \mathrm{~K}\left(688^{\circ} \mathrm{C}\right.$ and $\left.730{ }^{\circ} \mathrm{C}\right)$. Some compositions show a weak third exothermic peak between $1008 \mathrm{~K}$ and $1040 \mathrm{~K}\left(735^{\circ} \mathrm{C}\right.$ and $\left.767^{\circ} \mathrm{C}\right)$. It can be seen from Figure 1 that the position of the first exothermic peak varies only slightly with $\mathrm{Al}$ and $\mathrm{Si}$ additions when compared to that of Finemet. However, the second peak moves to higher temperatures when $x$ increases from 0 to 3.5 followed by small fluctuations for higher $x$ values. Overall, the difference between the primary and the secondary crystallization peak positions increases significantly with 3.5 at. pet substitution of Al followed by small decrease for 6 and 7 at. pct Al (Table I). These results imply that $\mathrm{Si}$ and $\mathrm{Al}$ substitutions improve the stability of the intergranular amorphous matrix phase that forms during primary crystallization compared to the Finemet composition (i.e., $\mathrm{Fe}_{73.5} \mathrm{Si}_{13.5} \mathrm{Nb}_{3} \mathrm{~B}_{9} \mathrm{Cu}_{1}$ ). The first exothermic peak, according to X-ray diffractometry, corresponds to the crystallization of the asspun, amorphous phase to the $\mathrm{Fe}_{3}(\mathrm{Si}, \mathrm{Al})$ phase (see also Figure 2), while the second crystallization peak is likely due to the clear formation of $\mathrm{Fe}_{3} \mathrm{~B}, \mathrm{Fe}_{2} \mathrm{~B}$ phases and possibly $\mathrm{Fe}-\mathrm{Nb}$ intermetallics from the residual amorphous matrix phase that persists after primary crystallization.

Figure 2 shows the XRD patterns of $\mathrm{Fe}_{65.5}$ $\mathrm{Si}_{16.5} \mathrm{Al}_{5} \mathrm{Nb}_{3} \mathrm{~B}_{9} \mathrm{Cu}$ ribbons before and after annealing. Similar diffractograms were obtained for all compositions. The ribbons in the as-spun state are clearly amorphous (Figure 2(a)). After annealing at $823 \mathrm{~K}$ $\left(550{ }^{\circ} \mathrm{C}\right.$ ) for 3600 seconds (which is approximately the temperature where the primary crystallization peak occurs), the $\mathrm{DO}_{3}-\mathrm{Fe}_{3}(\mathrm{Si}, \mathrm{Al})$ phase is formed as identified from the broad fundamental peaks and many weak superlattice peaks, especially $\{111\}$ and $\{200\}$. In addition to the crystalline phase, some residual amorphous phase exists as indicated from the extra breadth of the $\{220\}$ fundamental peak (Figure 2(b)). The fact that the $\mathrm{D}_{3}-\mathrm{Fe}_{3}(\mathrm{Si}, \mathrm{Al})$ is formed in such a wide range of $\mathrm{Fe}-\mathrm{Si}$ Al compositions is due to the large solubility of $\mathrm{Si}$ and

Table I. Thermal Analysis for the as-spun $\mathrm{Fe}_{87-z} \mathrm{Si}_{z-x} \mathrm{Al}_{x} \mathrm{Nb}_{3} \mathrm{~B}_{9} \mathrm{Cu}$ Ribbons

\begin{tabular}{lccr}
\hline Composition & $T_{x 1, \text { onset }}\left[\mathrm{K}\left({ }^{\circ} \mathrm{C}\right)\right]$ & $T_{x 2, \text { onset }}\left[\mathrm{K}\left({ }^{\circ} \mathrm{C}\right)\right]$ & $\Delta T_{x}\left[\mathrm{~K}\left({ }^{\circ} \mathrm{C}\right)\right]$ \\
\hline $\mathrm{Fe}_{73.5} \mathrm{Si}_{13.5} \mathrm{Nb}_{3} \mathrm{~B}_{9} \mathrm{Cu}_{1}$ & $794(521)$ & $942(669)$ & $148(-125)$ \\
$\mathrm{Fe}_{68} \mathrm{Si}_{15.5} \mathrm{Al}_{3.5} \mathrm{Nb}_{3} \mathrm{~B}_{9} \mathrm{Cu}_{1}$ & $789(516)$ & $984(711)$ & $195(-78)$ \\
$\mathrm{Fe}_{65.5} \mathrm{Si}_{16.5} \mathrm{Al}_{5} \mathrm{Nb}_{3} \mathrm{~B}_{9} \mathrm{Cu}_{1}$ & $795(522)$ & $991(718)$ & $196(-77)$ \\
$\mathrm{Fe}_{63.5} \mathrm{Si}_{17.5} \mathrm{Al}_{6} \mathrm{Nb}_{3} \mathrm{~B}_{9} \mathrm{Cu}_{1}$ & $798(525)$ & $985(712)$ & $187(-86)$ \\
$\mathrm{Fe}_{62} \mathrm{Si}_{18} \mathrm{Al}_{7} \mathrm{Nb}_{3} \mathrm{~B}_{9} \mathrm{Cu}_{1}$ & $805(532)$ & $992(719)$ & $187(-86)$ \\
\hline
\end{tabular}




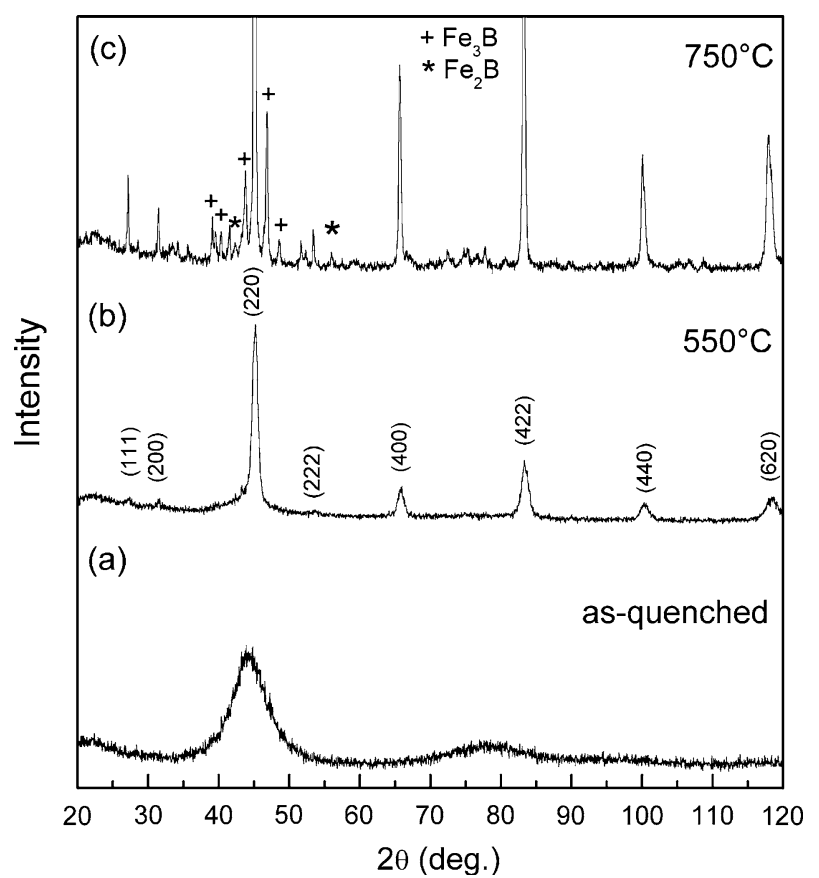

Fig. 2-X-ray Diffraction patterns of $\mathrm{Fe}_{65.5} \mathrm{Si}_{16.5} \mathrm{Al}_{5} \mathrm{Nb}_{4} \mathrm{~B}_{9} \mathrm{Cu}_{1}$ ribbons: (a) as-spun, (b) annealed at $823 \mathrm{~K}\left(550{ }^{\circ} \mathrm{C}\right) / 3600 \mathrm{~s}((h k l)$ shown for $\mathrm{D}_{3}$ phase), and (c) annealed at $1023 \mathrm{~K} / 3600 \mathrm{~s}$ (additional peaks marked for $\mathrm{Fe}_{3} \mathrm{~B}(+)$ and $\mathrm{Fe}_{2} \mathrm{~B}(*)$ phases).

$\mathrm{Al}$ in the $\mathrm{D}_{3}$ phase. After annealing at $750{ }^{\circ} \mathrm{C}$ (Figure 2(c)) (which corresponds to a temperature well above the second crystallization peak), some additional intermetallic phases form (namely $\mathrm{Fe}_{2} \mathrm{~B}$ and $\mathrm{Fe}_{3} \mathrm{~B}$ ). The $\mathrm{Fe}-\mathrm{B}$ compounds have tetragonal structure with stronger magnetocrystalline anisotropy ${ }^{[8,15]}$ which in combination with the coarsening of the grains (narrower diffraction peaks) contributes to the deterioration the soft magnetic properties of the alloy. Based on the breadth of the XRD peaks and using the Scherrer formula, we found that the average grain size for the samples annealed at $823 \mathrm{~K}\left(550^{\circ} \mathrm{C}\right)$ is between 9 and $11 \mathrm{~nm}$ diameter, independent of composition. This was confirmed by the TEM results as shown in the brightfield image of the $\mathrm{Fe}_{63.5} \mathrm{Si}_{17.5} \mathrm{Al}_{6} \mathrm{Nb}_{3} \mathrm{~B}_{9} \mathrm{Cu}_{1}$ ribbons annealed at $823 \mathrm{~K}\left(550{ }^{\circ} \mathrm{C}\right)$ (Figure 3). It can be clearly seen that the ribbon is composed of very small grains 10 to $15 \mathrm{~nm}$ in diameter embedded in an amorphous matrix. The selected area diffraction (SAD) shown in the inset of Figure 3 confirms the crystal structure of the $\mathrm{Fe}_{3}(\mathrm{Si}, \mathrm{Al})$ grains.

From the XRD peaks, we calculated the lattice constant of the $\mathrm{D}_{3}$ structure and the results are plotted as a function of $z$ (i.e. total $\mathrm{Si}+\mathrm{Al}$ substitution for $\mathrm{Fe}$ ) in Figure 4. It can be seen that the lattice constant decreases as $z$ increases. This means that when $\mathrm{Fe}$ is replaced by $\mathrm{Si}$ and $\mathrm{Al}$ atoms, the $\mathrm{D}_{3}$ unit cell becomes smaller. Due to the smaller size of the $\mathrm{Al}$ and $\mathrm{Si}$, the non-equilibrium nature of the processing, and the changes in the complex nature of lattice parameter with the composition in Fe-Si-Al alloys, a unique composition of the $\mathrm{D}_{3}$ phase was not determined. Previous studies on $\mathrm{Fe}-\mathrm{Si}$ alloys showed a linear decrease in the lattice parameter with the Si content. ${ }^{[16]}$ However, Fe-Al

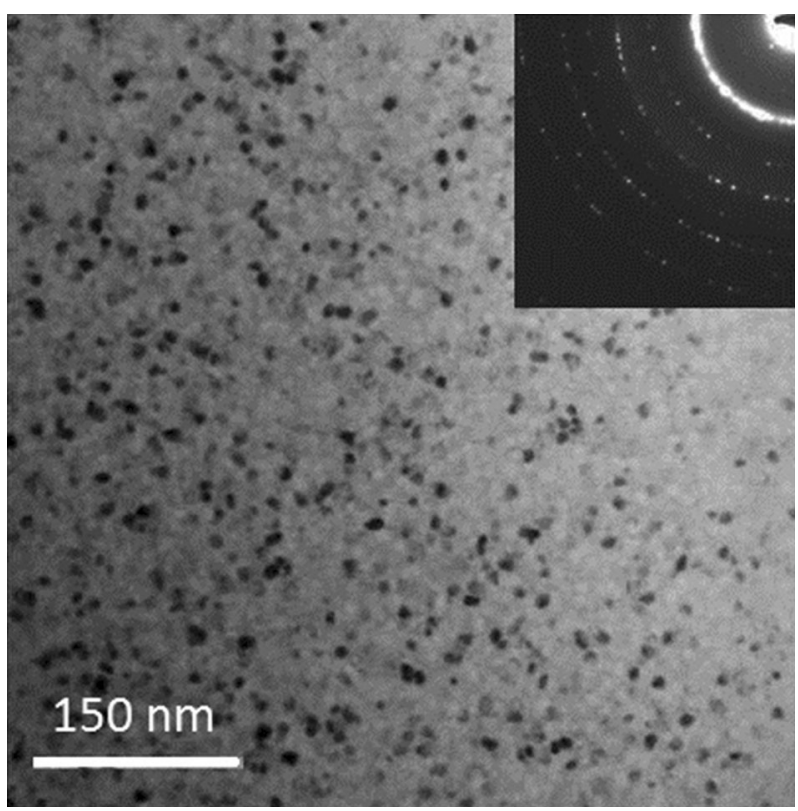

Fig. 3-Bright-field TEM image of $\mathrm{Fe}_{63.5} \mathrm{Si}_{17.5} \mathrm{Al}_{6} \mathrm{Nb}_{4} \mathrm{~B}_{9} \mathrm{Cu}_{1}$ annealed at $823 \mathrm{~K}\left(550{ }^{\circ} \mathrm{C}\right) / 3600 \mathrm{~s}$. The inset on the top right corner is a selected area diffraction image showing the diffraction rings from the $\mathrm{D}_{3}$ nanocrystals.

alloys showed a more complicated trend which is closely related to the changes in the magnetic valence with the Al content. ${ }^{[17]}$ In particular, they found that the lattice parameter in Fe-Al alloys increases up to $\sim 22$ at. pct Al, then it decreases up to $\sim 33$ at. pct Al. According to Taylor and Jones, ${ }^{[17]}$ this complexity can be attributed to the electron transfer to the Fe sites as $\mathrm{Al}$ is substituted for $\mathrm{Fe}$, thus decreasing both the radii of $\mathrm{Fe}$ and $\mathrm{Al}$. Another reason for the observed trend in our alloys is the fact that a significant portion of the $\mathrm{Al}$ atoms does not enter the $\mathrm{DO}_{3}$ structure but is segregated in the $\mathrm{Cu}$ clusters in a ratio $2: 1$ as suggested by the previous $3 \mathrm{D}$ atom probe analysis ${ }^{[18]}$ making the effect of $\mathrm{Si}$ on the crystal lattice parameter dominant.

Since in these alloys the averaging of the magnetocrystalline anisotropy is facilitated through the ferromagnetic intergranular amorphous phase, it is important to know the Curie temperature of the amorphous phase $\left(T_{\mathrm{C}}^{\mathrm{am}}\right)$, which dictates the upper temperature limit for applications. The Curie temperature of the as-quenched amorphous and the $\mathrm{Fe}_{3}(\mathrm{Si}, \mathrm{Al})$ phases in the annealed samples at $823 \mathrm{~K}$ $\left(550{ }^{\circ} \mathrm{C}\right)$ vs $z$ is shown in Figure 5 and delineated in Table II. Two trends can be discerned: (1) the Curie temperature of the $\mathrm{Fe}_{3}(\mathrm{Si}, \mathrm{Al})$ phase is generally higher than that of the amorphous phase; (2) the Curie temperature of each phase decreases with $\mathrm{Al}+\mathrm{Si}$ substitution. ${ }^{[18]}$ As suggested by the previously published atom probe tomography analysis, $\mathrm{B}$ and $\mathrm{Nb}$ atoms are strongly segregated in the residual amorphous phase whereas $\mathrm{Fe}, \mathrm{Si}$, and some of the $\mathrm{Al}$ atoms in the nanocrystalline phase. Therefore, the Fe substitution with $\mathrm{Si}$ and $\mathrm{Al}$ is expected to have a stronger effect on the crystalline than the amorphous phase. In addition, this declining trend of the Curie temperatures can be 


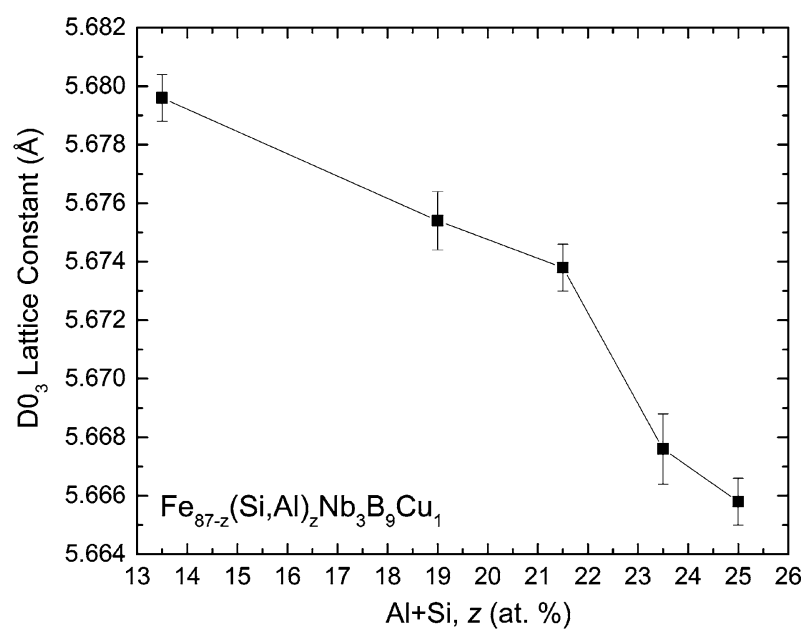

Fig. 4-Effect of $\mathrm{Si}$ and $\mathrm{Al}$ substitution for $\mathrm{Fe}$ on the lattice constant of the $\mathrm{D0}_{3}-\mathrm{Fe}_{3}(\mathrm{Si}, \mathrm{Al})$ grains for the $\mathrm{Fe}_{87-z} \mathrm{Si}_{z-x} \mathrm{Al}_{x} \mathrm{Nb}_{3} \mathrm{~B}_{9} \mathrm{Cu}_{1}$ alloys annealed at $823 \mathrm{~K}\left(550^{\circ} \mathrm{C}\right) / 3600 \mathrm{~s}$.

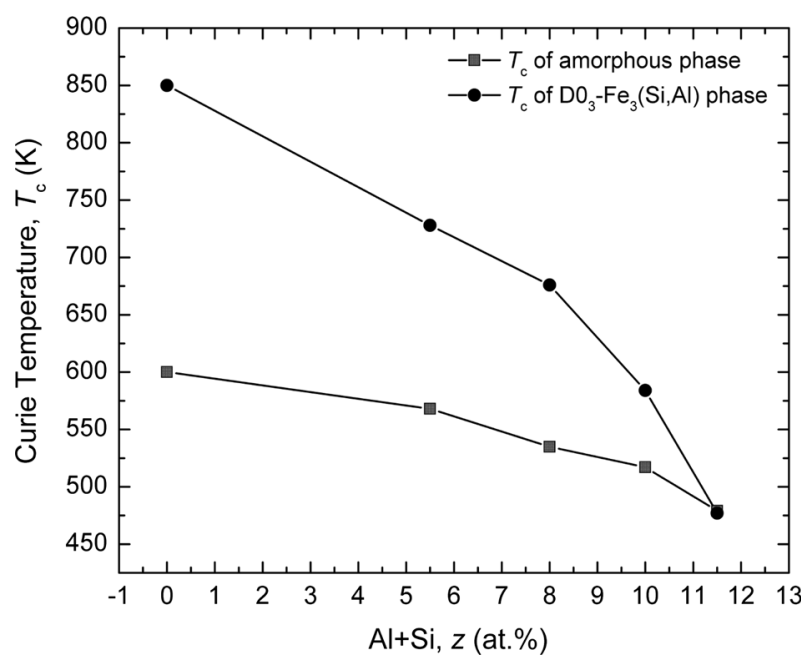

Fig. 5-Curie temperature of the amorphous phase in the as-spun ribbons and the crystalline phase in the annealed ribbons [at $823 \mathrm{~K}$ $\left(550{ }^{\circ} \mathrm{C}\right) / 3600$ s] with compositions $\mathrm{Fe}_{87-z} \mathrm{Si}_{z-x} \mathrm{Al}_{x} \mathrm{Nb}_{3} \mathrm{~B}_{9} \mathrm{Cu}_{1}$.

attributed to the weakening of the ferromagnetic interactions due to the Si and Al substitutions. Similar trends have been observed in the $\mathrm{Fe}-\mathrm{Si}-\mathrm{Al}$ ordered alloys ${ }^{[19]}$ and Fe-Si-B alloys. ${ }^{[20]}$

The effect of composition and annealing on the room temperature saturation magnetization of the as-spun and annealed ribbons is illustrated in Figure 6 with the room temperature saturation magnetization values presented in Table II. In both the as-spun and annealed ribbons, the magnetization decreases monotonically with the amount of $\mathrm{Si}+\mathrm{Al}$ substitution for $\mathrm{Fe}, z$. The decrease becomes steeper for the last two compositions, $z=23.5,25$. This trend can be attributed to (1) the absence of d-electrons in $\mathrm{Si}$ and $\mathrm{Al}$ atoms that dilute the magnetic moment of the alloy as they substitute for $\mathrm{Fe}$ in the parent composition (Finemet), (2) the electron transfer from $\mathrm{Si}$ and $\mathrm{Al}$ to $\mathrm{Fe}$ atoms reducing the $\mathrm{Fe}$ atomic moment, ${ }^{[17]}$ and (3) the fast decrease of the Curie temperature of both the as-spun amorphous phase and the crystalline $\mathrm{D}_{3}-\mathrm{Fe}_{3}(\mathrm{Si}, \mathrm{Al})$ phase with $z$ as discussed earlier. Another observation from Figure 6 is that after annealing, the saturation magnetization of the ribbons decreases slightly for the Finemet composition $(z=13.5)$ up to 35 pct in the $\mathrm{Fe}_{62} \mathrm{Si}_{18} \mathrm{Al}_{7} \mathrm{Nb}_{3} \mathrm{~B}_{9} \mathrm{Cu}_{1}$ $(z=25)$ ribbons.

The room temperature coercivity, $H_{\mathrm{c}}$, (Figure 7(a)) shows a minimum of $0.35 \mathrm{~A} / \mathrm{m}$ for $z=19$. Then it increases steadily with the increasing $z$, reaching 1.48 $\mathrm{A} / \mathrm{m}$ for $z=25 .^{[10]}$ All the room temperature coercivity values are summarized in Table II. Similar coercivity trends in Al-containing Finemet compositions have been observed by Todd et al. ${ }^{[21]}$ In nanocrystalline materials, the coercivity is a result of the average magnetocrystalline anisotropy, $\langle K\rangle$, rather the magnetocrystalline anisotropy constant, $K_{1}$, due to the small grain size and the exchange interaction between them. ${ }^{[3]}$ Room temperature $\langle K\rangle$ values were calculated using the $H_{\mathrm{c}}$ and $M_{\mathrm{s}}$ values from our measurements and Herzer's equations for $H_{\mathrm{c}}$ and $\langle K\rangle$ in the following way. First, we used the $\langle K\rangle=K_{1}^{4} \cdot D^{6} / J_{\mathrm{S}} \cdot A^{3} \quad$ (where $D=$ grain size, $A \approx 10^{-11} \mathrm{~J} / \mathrm{m}=$ exchange stiffness, $J_{\mathrm{s}}=$ saturation magnetization in Tesla, and $K_{1}$ (Fe-20 at. pct $\left.\mathrm{Si})=8 \times 10^{3} \mathrm{~J} / \mathrm{m}\right)$ equation $^{[3]}$ to calculate $\langle K\rangle$ for the Finemet composition $(x=0, z=13.5)$. By plugging this value into $H_{\mathrm{c}}=p_{\mathrm{c}} \cdot\langle K\rangle / J_{\mathrm{s}}$ (where $p_{\mathrm{c}}$ is a constant and $J_{\mathrm{s}}$ the magnetization in Tesla), we found that $p_{\mathrm{c}}=0.138$. Assuming that $p_{\mathrm{c}}$ does not change over the composition range, we used the relation $\langle K\rangle=H_{\mathrm{c}} \cdot J_{\mathrm{s}} /$ $p_{\mathrm{c}}$ to find the $\langle K\rangle$ for the rest of the compositions. The results are shown in Figure 7(b) where it can be seen that $\langle K\rangle$ follows the same trend as the coercivity.

Since the coercivity in the soft nanocrysrtalline alloys not only depends on the average magnetocrystalline anisotropy $\langle K\rangle,{ }^{[2]}$ but also on the magnetostriction, the room temperature magnetostrictive coefficient, $\lambda_{\mathrm{s}}$, was also measured across the composition series. The results of the as-spun and annealed samples are shown in Figure 8. The magnetostriction coefficient in the as-spun ribbons has large positive values due to the presence of the amorphous phase and it declines with the increasing $\mathrm{Al}+\mathrm{Si}$ substitution. After annealing at $823 \mathrm{~K}\left(550{ }^{\circ} \mathrm{C}\right)$, their magnetostriction values drop close to zero and for higher $\mathrm{Al}$ and $\mathrm{Si}$ amounts become slightly negative. This is a result of two contributions of opposite sign, a positive one from the amorphous phase and a negative one from the Fe-Si-Al crystallites. ${ }^{[3]}$ Similar behavior has been observed in other Finemet compositions with and without A1. ${ }^{[4,22,23]}$ From the measured $\lambda_{\mathrm{s}}$ values and assuming that the residual stress in the ribbons is $\sigma \approx 1.5 \mathrm{MPa}^{[8]}$ and independent of the composition, the stress anisotropy constant was calculated based on $K_{\sigma}=3 / 2 \cdot \lambda_{\mathrm{s}} \cdot \sigma$. The results are shown in Figure 7(b) where it can be seen that for all the Al-containing compositions, $K_{\sigma}$ is an order of magnitude or two smaller than the $\langle K\rangle$ values. Therefore, we can safely assume that the main contribution of the coercivity at room temperature is the average magnetocrystalline anisotropy, $\langle K\rangle$.

Since these alloys were primarily designed to have optimum magnetic properties at cryogenic tem- 
Table II. Magnetic parameters at $300 \mathrm{~K}$ and $77 \mathrm{~K}\left(27^{\circ} \mathrm{C}\right.$ and $\left.-196{ }^{\circ} \mathrm{C}\right)$ of the $\mathrm{Fe}_{87-z} \mathrm{Si}_{z-x} \mathrm{Al}_{x} \mathrm{Nb}_{3} \mathrm{~B}_{9} \mathrm{Cu}_{1}$ ribbons annealed at $823 \mathrm{~K}\left(550{ }^{\circ} \mathrm{C}\right)$ for $3600 \mathrm{~s}$

\begin{tabular}{llcccrr}
\hline Composition & $\begin{array}{c}M_{\mathrm{S}}(300 \mathrm{~K}) \\
\mathrm{A} \mathrm{m} / \mathrm{kg}\end{array}$ & $\begin{array}{c}M_{\mathrm{S}}(77 \mathrm{~K}) \\
\mathrm{A} \mathrm{m} / \mathrm{kg}\end{array}$ & $\begin{array}{c}H_{\mathrm{c}}(300 \mathrm{~K}) \\
\mathrm{A} / \mathrm{m}\end{array}$ & $\begin{array}{c}H_{\mathrm{c}}(77 \mathrm{~K}) \\
\mathrm{A} / \mathrm{m}\end{array}$ & $\begin{array}{c}T_{\mathrm{c}}(\mathrm{am}) \\
(\mathrm{K})\end{array}$ & $\begin{array}{c}\left.T_{\mathrm{c}}(\mathrm{Fe})_{3}(\mathrm{Si}, \mathrm{Al})\right) \\
(\mathrm{K})\end{array}$ \\
\hline $\mathrm{Fe}_{73.5} \mathrm{Si}_{13.5} \mathrm{Nb}_{3} \mathrm{~B}_{9} \mathrm{Cu}_{1}$ & 145 & 158.4 & $0.52 \pm 0.08$ & 0.81 & $600(327)$ \\
$\mathrm{Fe}_{68} \mathrm{Si}_{15.5} \mathrm{Al}_{3.5} \mathrm{Nb}_{3} \mathrm{~B}_{9} \mathrm{Cu}_{1}$ & 113.3 & 127.6 & $0.35 \pm 0.05$ & 1.26 & $568(295)$ & $728(577)$ \\
$\mathrm{Fe}_{65.5} \mathrm{Si}_{16.5} \mathrm{Al}_{5} \mathrm{Nb}_{3} \mathrm{~B}_{9} \mathrm{Cu}_{1}$ & 98.3 & 114.9 & $0.50 \pm 0.07$ & 0.58 & $535(262)$ & $676(403)$ \\
$\mathrm{Fe}_{63.5} \mathrm{Si}_{17.5} \mathrm{Al}_{6} \mathrm{Nb}_{3} \mathrm{~B}_{9} \mathrm{Cu}_{1}$ & 80.4 & 99.3 & $1.12 \pm 0.18$ & 0.45 & $517(244)$ & $584(311)$ \\
$\mathrm{Fe}_{62} \mathrm{Si}_{18} \mathrm{Al}_{7} \mathrm{Nb}_{3} \mathrm{~B}_{9} \mathrm{Cu}_{1}$ & 64.1 & 87.9 & $1.48 \pm 0.15$ & 1.45 & $479(206)$ & $476(203)$ \\
\hline
\end{tabular}

$T_{\mathrm{c}}(\mathrm{am})=$ Curie temperature of the as-quenched amorphous phase and $T_{\mathrm{c}}\left(\mathrm{Fe}_{3}(\mathrm{Si}, \mathrm{Al})=\right.$ Curie temperature of $\mathrm{D} 0_{3}$ crystalline phase.

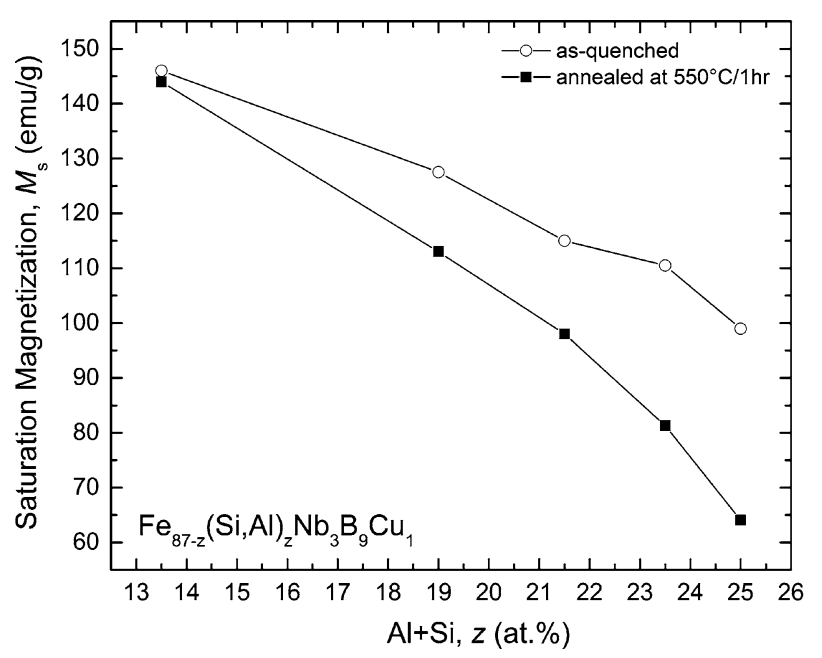

Fig. 6-Variation of the room temperature saturation magnetization with composition for the as-spun and annealed [at $823 \mathrm{~K}\left(550^{\circ} \mathrm{C}\right) /$ $3600 \mathrm{~s}] \mathrm{Fe}_{87-z} \mathrm{Si}_{z-x} \mathrm{Al}_{x} \mathrm{Nb}_{3} \mathrm{~B}_{9} \mathrm{Cu}_{1}$ alloys.

peratures, it is important to investigate their magnetic performance not only at room temperature but also at lower temperatures. The results are summarized in Figure 9 where the temperature dependence of the saturation magnetization $\left(M_{\mathrm{S}}\right)$ and coercivity $\left(H_{\mathrm{c}}\right)$ of the annealed ribbons are plotted. As expected, $M_{\mathrm{S}}$ increases steadily as the measuring temperature decreases due to the reduced thermofluctuations of the magnetic moments. The increase seems to be slightly stronger for the ribbons with the highest amount of $\mathrm{Al}$ and $\mathrm{Si}$ contents (Figure 9(a)). This is probably due to the lower Curie temperatures associated with these compositions. On the other hand, the temperature dependence of the coercivity is more complicated and changes significantly with the addition of $\mathrm{Al}$ and $\mathrm{Si}(z)$ (Figure 9(b)).

For the first three compositions $(z=13.5,19$, and $21.5)$, coercivity increases as temperature decreases. More specifically for $z=13.5$ and $21.5, H_{\mathrm{c}}$ reaches a shallow maximum at $T=200 \mathrm{~K}\left(-73{ }^{\circ} \mathrm{C}\right)$ before it begins to slightly decline at lower temperatures, whereas for $z=19$ it increases continuously. At $z=23.5$ and 25 , the temperature trend of the coercivity reverses; $H_{\mathrm{c}}$ decreases with the decrease in temperature to about $150 \mathrm{~K}\left(-123^{\circ} \mathrm{C}\right)$ and then either remains stable $(z=23.5)$ or increases slightly $(z=25)$. The lowest measured coercivity at $77 \mathrm{~K}\left(-196^{\circ} \mathrm{C}\right)$ is $0.45 \mathrm{~A} / \mathrm{m}$ and it was obtained for $z=23.5$. This value is lower than

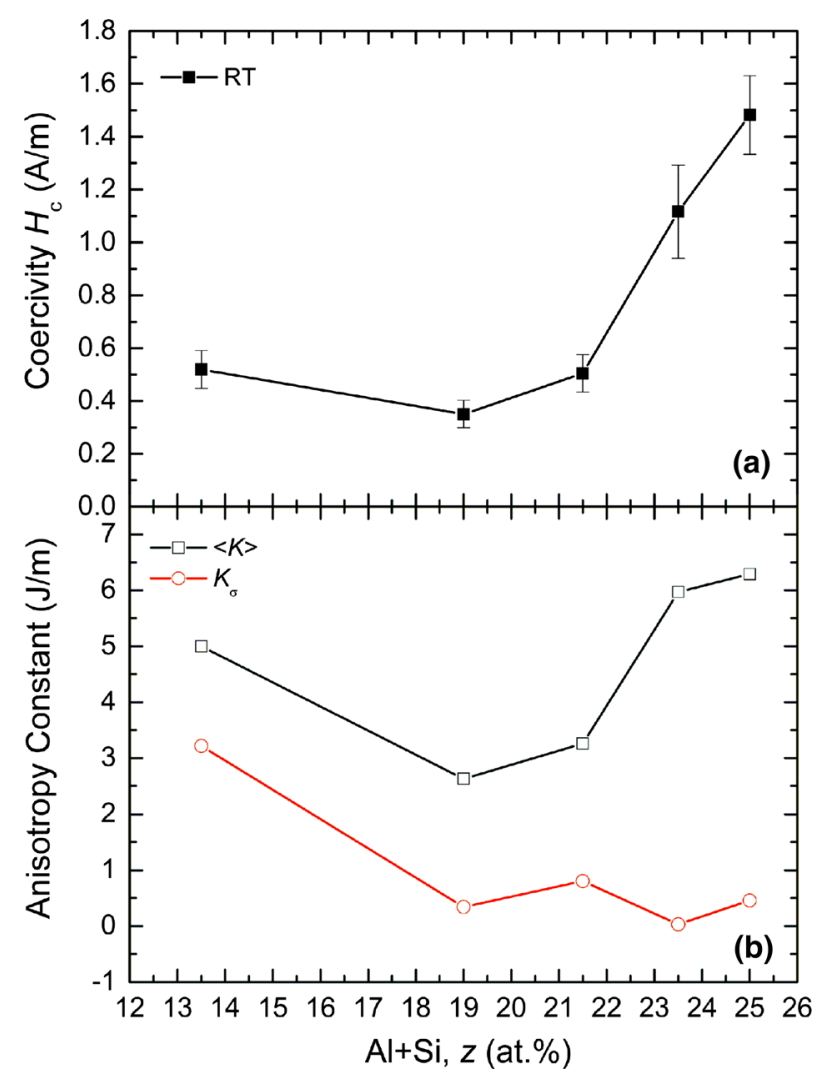

Fig. 7-Room temperature coercivity of the annealed ribbons for varying $\mathrm{Fe}_{87-z} \mathrm{Si}_{z-x} \mathrm{Al}_{x} \mathrm{Nb}_{3} \mathrm{~B}_{9} \mathrm{Cu}_{1}$ compositions $(a)$ and calculated average magnetocrystalline anisotropy $\langle K\rangle$ and stress anisotropy, $K_{\sigma}$ constants $(b)$.

that of the commercially available Cryoperm-10 alloy (i.e., $\mathrm{Ni}_{77.4} \mathrm{Fe}_{15.9} \mathrm{Cu}_{4.2} \mathrm{Mo}_{1.5} \mathrm{Mn}_{1.0}$ ) designed by Vacuumschmelze to operate at 4.2 to $77 \mathrm{~K}\left(-196{ }^{\circ} \mathrm{C}\right)$, which has an $H_{\mathrm{c}}$ of $1.2 \mathrm{~A} / \mathrm{m}^{[10]}$

The different temperature trends of the coercivity we observed can be attributed to the combined effect of temperature dependence of the magnetocrystalline anisotropy and magnetostriction. By changing the ratio of Fe:Si:Al, we change the temperature where both $K_{1}$ and $\lambda$ have values near zero, which enable lower coercivity. A rarely observed change in the sign of $K_{1}$ requires a zero value at some temperature, which is sensitively dependent on the composition of the alloy. This specific feature of $(\mathrm{Fe}, \mathrm{Si}, \mathrm{Al})$ alloys was observed by Takahashi, et al. using FeSiAl single-crystal samples and 


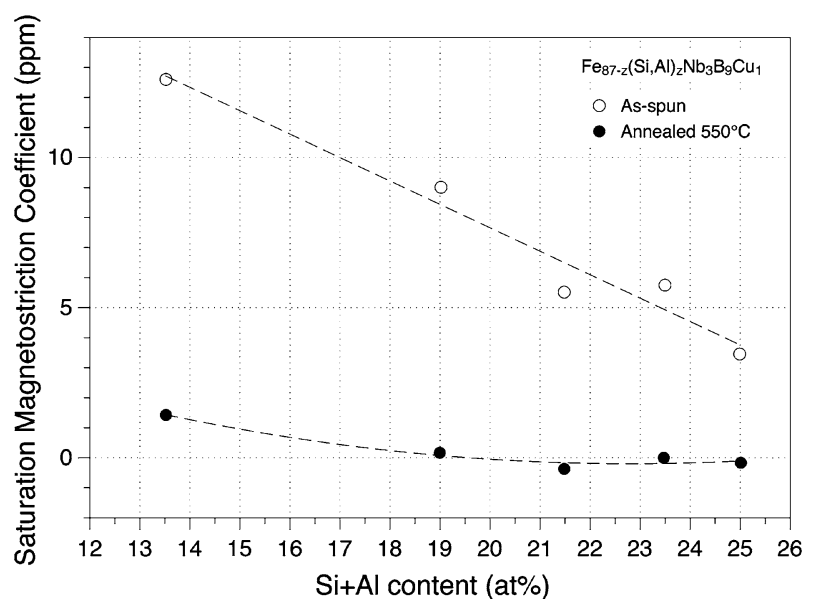

Fig. 8-Room temperature saturation magnetostriction as a function of composition for the as-spun and annealed [at $823 \mathrm{~K}\left(550{ }^{\circ} \mathrm{C}\right)$ 3600 s] $\mathrm{Fe}_{87-z} \mathrm{Si}_{z-x} \mathrm{Al}_{x} \mathrm{Nb}_{3} \mathrm{~B}_{9} \mathrm{Cu}_{1}$ alloys.

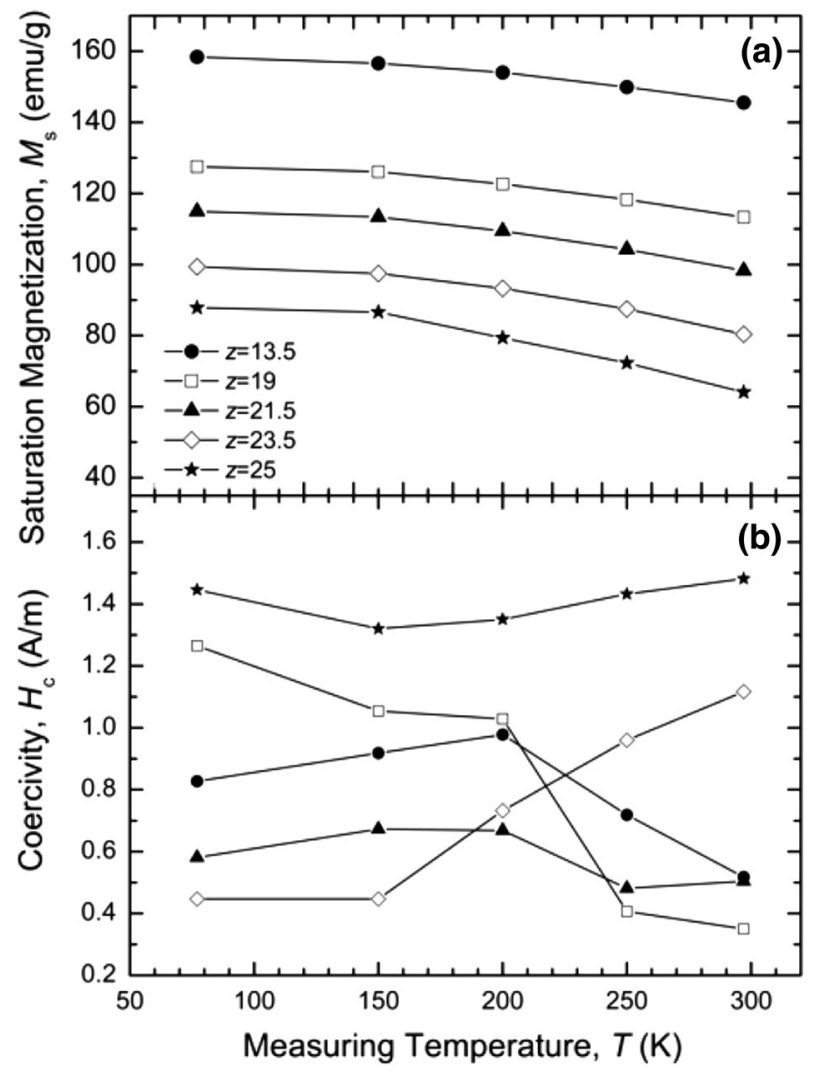

Fig. 9-Low temperature dependence of $(a)$ the saturation magnetization $\left(M_{\mathrm{S}}\right)$ and $(b)$ coercivity $\left(H_{\mathrm{c}}\right)$ of the annealed $\left[823 \mathrm{~K}\left(550{ }^{\circ} \mathrm{C}\right) /\right.$ 3600 s] $\mathrm{Fe}_{87-z} \mathrm{Si}_{z-x} \mathrm{Al}_{x} \mathrm{Nb}_{3} \mathrm{~B}_{9} \mathrm{Cu}_{1}$ ribbons.

is illustrated in Figure 3 of Reference 12 and Figure 2 in Reference 11. This known change in sign with composition in 'large-grained' (or single crystal) alloys was used as an alloy design principle for the development of fine-grained alloys. Although we did not measure the temperature dependence of the magnetocrystalline anisotropy in our samples, we believe that like in Takahashi alloys the slight variation in $\mathrm{Si} / \mathrm{Al}$ content for

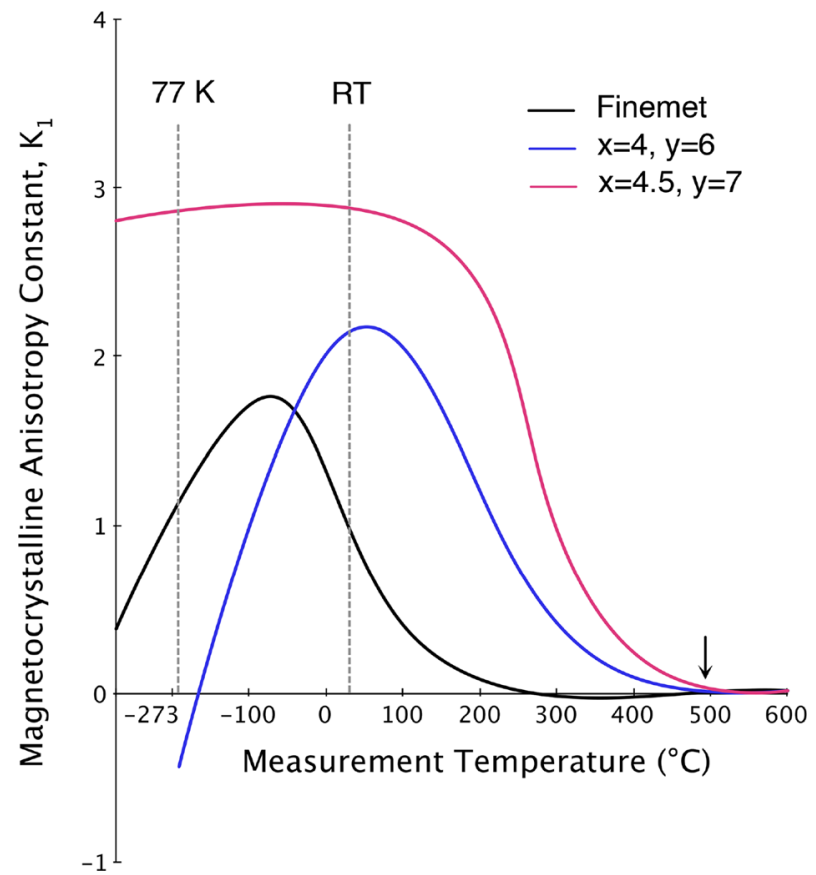

Fig. 10 - Schematic diagram of the proposed variation in magnetocrystalline anisotropy for three of the $\mathrm{Fe}_{87-z} \mathrm{Si}_{z-x} \mathrm{Al}_{x} \mathrm{Nb}_{3} \mathrm{~B}_{9} \mathrm{Cu}_{1}$ alloys $(z=13.5,23.5$, and 25$)$.

the related alloys results in a large change in the temperature at which the magnetocrystalline anisotropy changes sign. A schematic diagram that is consistent with what we know about the $K_{1}(\mathrm{~T})$ for (Fe,Si,Al), (Fe,Si), and our samples is graphically shown in Figure 10 for three representative compositions. Of course, the temperature dependence of magnetostriction is another factor that determines the coercivity at low temperatures too; however, we were also unable to measure this quantity at cryogenic temperatures. In addition, as it was mentioned earlier, the magnetostriction in these nanocomposite ribbons has two contributions of opposite sign, i.e., from the Fe-Si-Al grains and the amorphous matrix, which may have completely different temperature trends. According to Takahashi ${ }^{[11]}$ in the Fe-Si-Al single crystals, both magnetostrictive coefficients, $\lambda_{100}$ and $\lambda_{111}$, change sign from negative to positive with the decreasing temperature. However, it is not known how the magnetostrictive coefficient of the amorphous phase varies with temperature making it even more difficult to predict the non-equilibrium multiphase samples.

\section{CONCLUSIONS}

In this work, we successfully designed and fabricated a series of (Fe-Si-Al)-based soft nanocrystalline alloys with the intention of improving their magnetic performance at cryogenic temperatures. It was found that $\mathrm{Si}$ and Al substitutions for Fe has the following effects:

1. Stabilize the nanocrystalline $\mathrm{DO}_{3}-\mathrm{Fe}_{3}(\mathrm{Si}, \mathrm{Al}) \mathrm{mi}-$ crostructure by increasing the temperature differ- 
ence between the primary and secondary crystallization peak.

2. Decrease the lattice parameter of the $\mathrm{D}_{3}-\mathrm{Fe}_{3}(\mathrm{Si}, \mathrm{Al})$ phase, the Curie temperature of the amorphous and the crystalline phase, and the saturation magnetization of the ribbons.

3. Decrease the room temperature coercivity to $0.35 \mathrm{~A} / \mathrm{m}$ when used at small amounts $(x=3.5$, $z=19)$.

4. Change the temperature dependence of the coercivity. The lowest coercivity, $0.45 \mathrm{~A} / \mathrm{m}$, was obtained at $77 \mathrm{~K}\left(-196{ }^{\circ} \mathrm{C}\right)$ for the $\mathrm{Fe}_{63.5} \mathrm{Si}_{17.5} \mathrm{Al}_{6} \mathrm{Nb}_{3} \mathrm{~B}_{9} \mathrm{Cu}_{1}$ ribbons, which is comparitively lower that that obtained for the commercially available alloy, and hence is favorable for cryogenic applications.

\section{ACKNOWLEDGMENTS}

The authors would like to acknowledge the help of R. Goswami in the measurement of TEM samples. The work was supported by the Office of Naval Research under contract N00014-12-WX-2-1328. This work was completed in part at the U.S. Naval Research Laboratory.

\section{REFERENCES}

1. Y. Yoshizawa, S. Oguma, and K.Y. Yamaguchi: J. Appl. Phys., 1988, vol. 64 (10), pp. 6044-46.

2. G. Herzer: IEEE Trans. Magn., 1989, vol. MAG-25 (5), pp. 3327-29.

3. G. Herzer: Mater. Sci. Eng. A, 1991, vol. 133, pp. 1-5.
4. V.H. Duong, R. Grössinger, R. Sato Turtelli, and Ch. Pola: $J$. Magn. Magn. Mater., 1996, vols. 157-158, pp. 193-94.

5. J.H. Claassen: IEEE Trans. Appl. Supercond., 2005, vol. 15 (2), pp. $2385-88$

6. T. Nakata, N. Takahashi, K. Fugiwara, M. Nagano, and M. Seno: J. Magn. Magn. Mater., 1992, vol. 112, pp. 174-76.

7. M. Chen, Y.J. Yu, L.Y. Xiao, Q.L. Wang, W. Chung, K. Lim, and S.K. Baang: IEEE Trans. Appl. Supercond., 2003, vol. 13, pp. 2313-16.

8. M.A. Willard and M. Daniil: Handbook of Magnetic Materials, Chap. 4, Elsevier, Amsterdam, 2013, vol. 21, pp. 173-342.

9. M.A. Willard and T.M. Heil: J. Appl. Phys., 2007, vol. 101, p. 09 N 113 .

10. M. Daniil, M.S. Osofsky, D.U. Gubser, and M.A. Willard: Appl. Phys. Lett., 2010, vol. 96, p. 162504.

11. M. Takahashi, H. Arai, and T. Wakiyama: IEEE Trans. Magn., 1987, vol. MAG-23 (5), pp. 3523-25.

12. M. Takahashi, H. Arai, Y. Tanaka, and T. Wakiyama: IEEE Trans. Magn., 1986, vol. MAG-22, pp. 638-40.

13. B.D. Cullity: Elements of X-Ray Diffraction, $2^{\text {nd }}$ ed., AddisonWesley, Reading, MA, 1978, pp. 102, 359-63.

14. J.H. Claasen, M.A. Willard, and V.G. Harris: Rev. Sci. Instr., 2002, vol. 73 (9), pp. 3265-67.

15. R. Coehoorn, D.B. de Mooij, and C. de Waard: J. Magn. Magn. Mater., 1989, vol. 80, pp. 101-04.

16. L.K. Varga, F. Mazaleyrat, J. Kovac, and J.M. Greneche: J. Phys. Condens. Mater., 2002, vol. 14, pp. 1985-2000.

17. A. Taylor and R.M. Jones: J. Phys. Chem. Solids, 1958, vol. 6, pp. 16-37.

18. M. Daniil, K.E. Knipling, H.M. Fonda, and M.A. Willard: New J. Phys., 2014, vol. 16, p. 055016.

19. E. Legarra, E. Apiñaniz, F. Plazaola, J.A. Jimenez, and A.R. Pierna: J. Magn. Magn. Mater., 2008, vol. 320, pp. e688-91.

20. F.E. Luborsky, J. Becker, J. Walter, and H. Liebermann: IEEE Trans. Magn., 1979, vol. 15 (3), pp. 1146-49.

21. I. Todd, B.J. Tate, H.A. Davies, M.R.J. Gibbs, D. Kendall, and R.V. Major: J. Magn. Magn. Mater., 2000, vols. 215-216, pp. 27275.

22. V.H. Duong, R. Sato Turtelli, and R. Grössinger: IEEE Trans. Magn., 1996, vol. 32, pp. 4821-23.

23. B.J. Tate, B.S. Parmar, I. Todd, H.A. Davies, M.R.J. Gibbs, and R.V. Major: J. Appl. Phys., 1998, vol. 83 (11), pp. 6335-37. 